Available online at $\quad$ http://www.jfas.info

\title{
THE PROSPECTS OF USE OF ALTERNATIVE TYPES OF FUEL IN ROAD TRANSPORT
}

\author{
L. M. Gabsalikhova*, G. R. Sadygova, I. V. Makarova, E. M. Mukhametdinov \\ Kazan Federal University, Naberezhnye Chelny
}

Published online: 08 August 2017

\begin{abstract}
The article is devoted to the analysis of possibilities of using alternative types of fuel in transport. Gas engine fuels are considered as potential energy carriers for diesel engines. Since the constructions of vehicles, using gas and traditional types of fuel, have some differences, the most important are the issues of ensuring trouble-free operation: the reliability of design, the development of petrol station chain, and the corporate service system. One of the ways of solving the problem of forecasting the need to expand the network of gas-filling stations for natural gas vehicles (NGV)is presented in the work. It is implemented in the form of program module that allows taking into account the prospects for expansion of the natural gas vehicles park, as well as the risks, which may arise in the process of realization of the long-term strategies for the development of this direction. The issues of ensuring the operational reliability of $\mathrm{NGV}$ are considered. The developed methods are aimed at improving the corporate service system of PJSC "KAMAZ". Fundamental defects of gasengines and failures distribution, depending on the operational kilometers, arising in the warranty period of operation, are analyzed in the work.
\end{abstract}

Keywords: transport, alternative types of fuels, natural gas vehicle fuel, reliability.

\section{INTRODUCTION}

In the Russian Federation, as in other developed and developing countries, transport is an important component of social and industrial infrastructure. The rapid increase in the level of auto mobilization, which, along with the development, creates serious problems for humanity,

Author Correspondence, e-mail: muhametdinoval@mail.ru

doi: http://dx.doi.org/10.4314/jfas.v9i2s.62 
Is connected with an increase in the need for fuel resources and the environmental pollution The problem of environmental pollution is the most critical for large and medium-sized cities. According to the World Health Organization, from $40 \%$ to $50 \%$ of human diseases can currently be associated with environmental change and, first of all, with the pollution of atmosphere, as the quality of air basin is the key factor, which has a negative impact on the state of the city's natural environment [1].

The key factors, influencing air pollution, caused by emissions from road transport, are the increase in auto mobilization, the peculiarities of type and age structure of park, the poor quality of motor fuel, and the increase in the volume of road carriages.

Almost the whole automobile park uses oil fuel, however, according to pessimistic estimations, depletion of oil reserves in industrialized countries will come in the next few years. In Russia, according to the OPEC forecast, oil will be sufficient until 2021, and gas until 2083. If today about $5 \%$ of the demand for oil remains unsatisfactory, then by 2025 the deficit may amount to $12 \%$. Due to this, there is the task for the search of alternative sources of motor fuel, which would meet high ecological requirements. The prerequisites for the search of alternative fuels are the need to reduce the dependence of economy on oil products, which is especially important for transport; the observance of ecological standards "EURO" $[2]$.

\section{RESEARCH METHODS}

The assessment of promising areas for the development of automotive market was carried out by way of analyzing literature sources, as well as statistics on the failure of trucks, operating on traditional fuels and compressed natural gas. For car manufacturers, the use of alternative fuels is currently relevant. The works of Bondarenko E.V. [3], Kornilov G.S. [4] are devoted to the increase in fuel efficiency and environmental compatibility of automobile transport. Currently, for the engines of internal combustion, the practice of applying of various types of alternative fuels is known (Figure 1). 


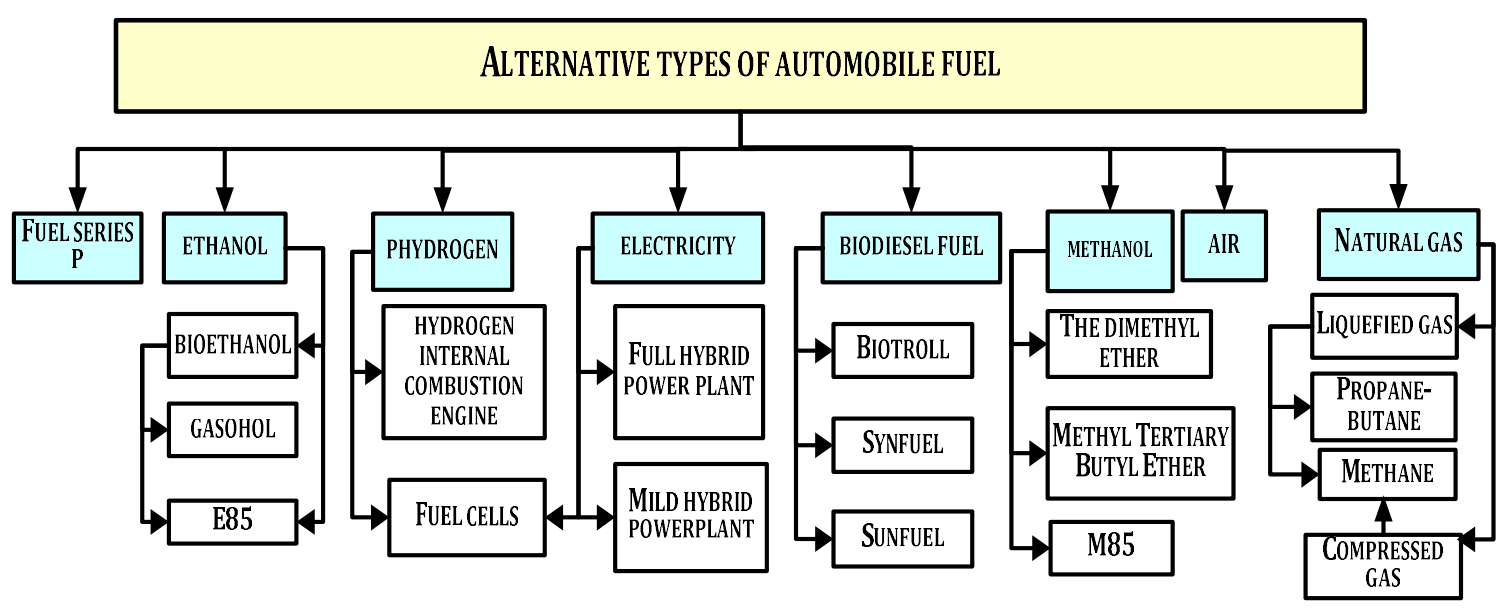

Fig.1. Alternative types of automobile fuel

Natural gas, as motor fuel, is used in several forms: compressed natural gas (CNG), liquefied natural gas (LNG), and associated natural gas - or liquefied petroleum gas (LPG) $[5,6]$. At the same time, LNG vehicles are already used throughout the world: technologies for liquefied natural gas production, storage and use are developed, as well as there is a wide range of LNG vehicles (about four million in the world). Compressed natural gas as a motor fuel is widely used in countries with their own natural gas reserves. Due to the fact, that such fuel has an increased octane number in comparison with traditional fuels, vehicles are more environmentally friendly, and therefore find application as a public transport [7].

The deliberate attention of researchers to the prospects of transport sector development is due to the fact, that many factors, affecting both the stability of transport system itself, and those, which can cause serious consequences for other areas of activity, require the development of new methods to predict their future. In general, the works are carried out in two directions:

- new technical and technological solutions, aimed at improving the quality of fuel, switch to low-carbon fuels, changing the way of energy obtaining, fundamentally new types of powergenerating plants, as well as the use of new materials and design solutions to reduce the weight of the vehicles.

- organizational and management decisions, aimed at improving the efficiency of vehicle operation, including by means of organization of their qualitative and timely service and repair, preventing failures, improving operational reliability and safety $[8,9]$.

Considering the possibilities of alternative fuels use in road transport, it is necessary to take into account the long-term demand among consumers. Since the consumer is not always ready to refuse from the usual vehicles, perspective engines should be used in those segments of the 
market, where the state can most effectively generate demand, using various methods of encouragement.

The authors of the article [10] consider bio-diesel fuel as an alternative. They believe that not only technical aspects, but also economic, social and strategic aspects of modern society should be taken into account.

Analyzing potentially possible sources of alternative fuels, the authors of the research state, that it is necessary to take into account the cumulative impact (i.e. not only while vehicle operation, but also in the process of obtaining the energy for operation, and the possibility of utilization, that largely refers to the recycling of batteries of electric vehicles and hybrids), as well as the present value of useful transport work. In the article [11] the prospects of using hydrogen fuel cells in road transport are analyzed. The authors compare the full cycle of costs "from pipe to wheel", distinguishing six steps of the chain of full fuel cycle: production and preparation of the main fuel, transportation of primary fuel, processing of fuel for cars, transportation of fuel to filling station, storage of fuel and transformation of motor fuel into useful energy. As a result of the research, the authors found, that along with electric vehicles and vehicles with hydrogen fuel cells, hybrid cars in the diesel version have the lowest conversion losses of automobile fuel into useful energy and proportionally reduce losses in the field of fuel processing and transportation, due to higher efficiency of transport means, compared with internal combustion engines of trucks. Another promising option is natural gas. Therefore, the most efficient vehicles, based on the full fuel cycle, are natural gas, fuel cells and diesel hybrids. As for the use of hydrogen fuel cells, the authors consider the direction to be promising, but expensive.

To reduce emissions in cities, management decisions are used both to regulate the density of traffic flows and to optimize the park of vehicles. The last is renewed or replaced with more environmental friendly transport facilities, with the aim to regulate its type-age structure. In addition, taking into account the fact, that buses, delivery light trucks, and utility vehicles, using mainly diesel fuel, are operated in the city cycle, the comparison of used vehicles with their alternative counterparts is based on economic, environmental and social criteria.

The authors of the study [12], based on the analysis of the cost of creation the conditions for transition to the use of buses on alternative fuel of various types, conclude that the most important prerequisite for such a transition is the willingness of cities and bus operators to apply such new technologies. The decision-maker should feel the importance of environmental benefits of such vehicles, because from a purely economic point of view, these buses are more costly. The efficiency of transport can be estimated using the energy 
efficiency, according to the formula: $\mathrm{EE}$ in $\%=100 /$ (specific fuel consumption in $\mathrm{kg} / \mathrm{kW} * \mathrm{~h}$ * fuel calorific value (specific heat) in $\mathrm{kW}^{*} \mathrm{~h} / \mathrm{kg}$ ). At the same time, this indicator can be regulated by the state [13].

The author of the article [14], for assessing the efficiency of transport, identifies two main areas: fuel efficiency and park efficiency. Herewith, fuel efficiency is a form of thermal efficiency, depending on the unique parameters of the engine, aerodynamic drag, weight, and rolling resistance of the vehicle, while the efficiency of the park describes the use of fuel by a group of vehicles, that can be increased both by improving the characteristics of a single vehicle, and the route optimization or behavior modification.

\section{RESULTS}

The most realistic alternative for traditional vehicles with diesel and gasoline engines in Russia are transport facilities with natural gas vehicle fuel, in particular methane.

An important factor, determining the feasibility of using alternative fuels is the proximity of its properties to the properties of petroleum fuels that allows minimizing the cost of adapting serial ICE to work with this alternative fuel. In addition, the proximity of these properties makes it possible to use the existing infrastructure for fuel storage and filling with them vehicles and other power plants.

The feature of gas engine facilities is that, they require more frequent refueling, that in turn requires more gas filling stations. Since the main deterrent in the development of this direction is the unpreparedness of the infrastructure to mass use of transport facilities with gas engines, it is necessary to assess the risks, connected with the implementation of this project. The development of infrastructure provides for the expansion of the network of NGVrefuelling compressor stations (CNG Filling Station), as well as the network of service centers [15], which have the sites for servicing compressed gas vehicles.

Developed method makes it possible to forecast the demand for CNG filling stations, under optimistic and pessimistic scenarios of the growth in the number of park of compressed gas vehicles, as well as to assess the situation in case of a fixed risk of reducing its growth.

The initial data for calculating the demand for filling stations, depending on the structure of vehicles park are the following: the calculation period - $T$, the number of compressed gas buses for the period - A, the number of other compressed gas vehicles for the period $\mathrm{B}$, the coefficient of permissible reduction of the park - S, the standard series of CNG filling stations (according to capacity) - Z. 
According to the current trend, if the capacity of existing gas filling stations will satisfy the needs now and after two years, taking into account the growth in the number of compressed gas vehicles, in relation to the initial year $\mathrm{t}>\mathrm{T}-2$, there is no need for the construction of filling station. If, as a result of the increase in the number of park, the number of refueling runs of transport facilities will exceed the capacity of existing gas stations $\Delta t<Z 1$, then a decision should be made to build new CNG filling station. In case, if the construction of new gas filling stations is required, the incremental amount of park number is calculated and, accordingly, the number of refueling runs is forecasted, i.e. the necessary increase in the capacity of gas filling stations:

$$
\Delta t=\left(B_{t+2}-B_{t}\right) * 104+\left(A_{t+2}-A_{t}\right) * 296
$$

where, 104 - is the number of refueling runs of other vehicles to CNG filling station;

$B_{t+2}-$ is a park of other vehicles for the calculation period;

$B_{t}$-is a park of other vehicles for the current period;

296 -is a number of refueling runs of buses to CNG filling station;

$A_{t+2}-$ is a bus park for the calculation period;

$A_{t}$ - is a bus park for the current period.

When deciding on the construction, the choice of the capacity of filling station is carried out by comparing the forecasted requirements in the number of refueling runs with the existing standard series of CNG filling stations: the variant, which is correspond with the current and future needs more precisely, is chosen.

$$
\begin{gathered}
P_{t}^{m-1}=P_{t}^{m-1}+1 \\
\Delta t=\Delta t-Z_{m-1}
\end{gathered}
$$

Viewing the standard series of CNG filling stations can be done using a form, openingin the menu "Regulatory data". The same form provides the opportunity to view regulatory data on the number of car arrivals per year to a gas filling station. Calculations are carried out for each period, depending on the dynamics of growth in the size of park of compressed gas vehicles. To simulate the scenario of development of the compressed gas vehicles park and the need for filling stations under the influence of various types of risks, the coefficient of reduction the park number -S is introduced, which shows the allowable lower limit of the number of compressed gas vehicles park $\Delta t S=\Delta t * S$. The calculation of the need for filling stations for 
this case is similar. The algorithm of the method, implemented in the form of a software module, is shown in Figure 2.

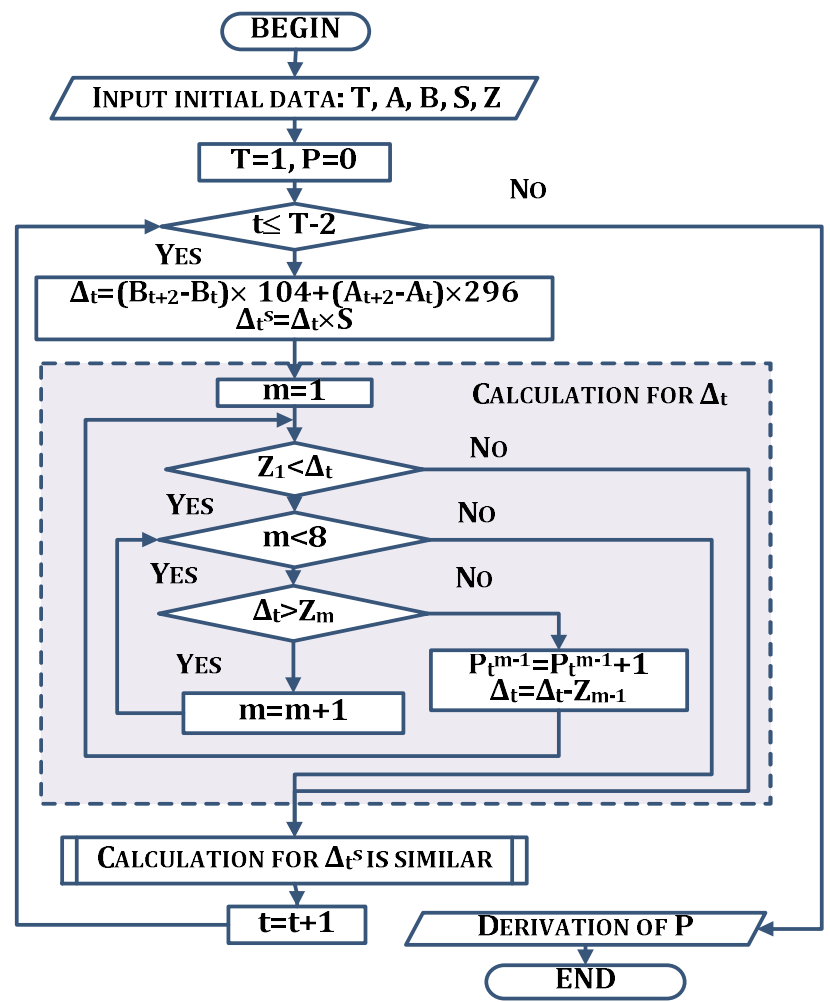

Fig.2. Algorithm of creation of the development strategy of $\mathrm{CNG}$ filling station network

The program module allows predicting the need for CNG filling stations in accordance with the forecasts of expansion of compressed gas vehicles parkin each region, taking into account the risks [16]. It contributes to a more justified choice of strategy for expanding the park of compressed gas vehicles in the region.

The demand and satisfaction of transport facilities owners also depend on their reliability and the development of corporate service system, especially in the warranty period of operation. Since vehicles, using gas engine fuel, have some differences with traditional ones, there are a number of problems, arising when their share in the park number increases.

Leading world and Russian car manufacturers produce more than 80 models of cars, buses and other modes of transport, using natural gas. Production of compressed gas vehicles and buses, using compressed natural gas was also developed by PJSC "KAMAZ". Their design uses advanced technical solutions, which significantly reduce the adverse impact of vehicles on the environment. A special feature of the design of gas engines $(820.73,820.74,820.60$, 
820.61 ) is the presence of turbocharger, charge air cooler, electronic control and exhaust gas after treatment system.

The success of new product depends both on engineering solutions (product reliability) and on marketing policy (price, guarantees). The cost of maintenance under the warranty depends on the reliability of the product, so the manufacturer can extend warranty obligations if it is confident in the reliability of products. The matters of reliability, price and guarantees should be considered in a comprehensive manner. When examining questions about the price and duration of the guarantee period, the authors of the research note, that the initial information for calculations should be data on failures during the guarantee period, because the adequacy of the made decisions depends on the quality of information $[18,19]$. Since the reasons for failures can be caused by various factors, which are heterogeneous, then it is necessary to have a tool for processing large data files, including text [20]. For forecasting, various methods of data mining are used, including neural network algorithms [21].

Experience in the operation of KAMAZ vehicles shows, that the main failures of gas engines during the warranty period of operation fall to the first 8 thousand $\mathrm{km}$. (Figure 3).

Since the largest number of complaints, related to gas engine failures, is caused by defects in sparkling plugs and spark coils, gas dispensers, ignition, phase sensor and the sensor of turning on the electromagnetic coupling, it is necessary to investigate the causes of failure. The results of the study should be the following recommendations:

- for manufacturers - to improve the quality and reliability of these structural elements;

- for owners of vehicles - according to the peculiarities of operation;

- for service specialists - to improve technical service.
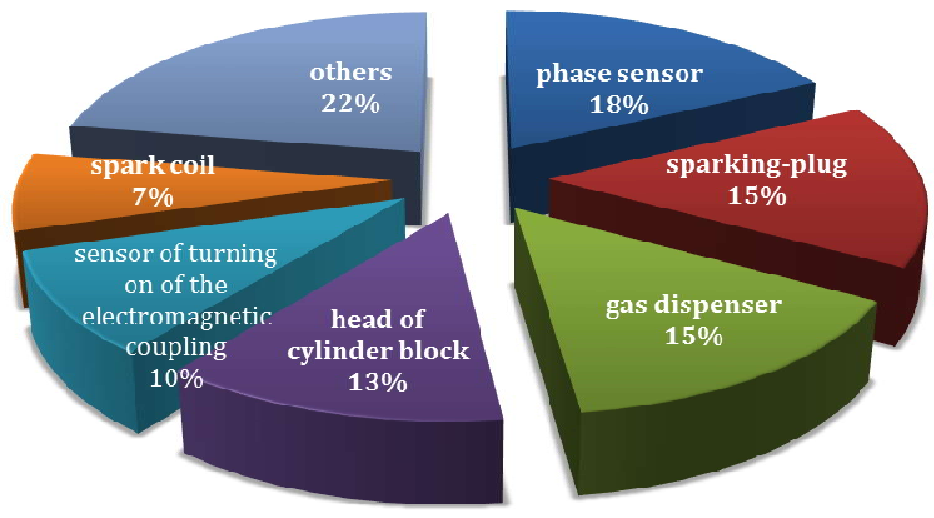

Fig.3. The structure of the causes of complaints on the gas engine 
Work with suppliers and the identification of unreliable items allows to increase the reliability of a car as a whole. So, it is obviously, that the system, all elements of which will be equally reliable or, at least, close in reliability, will be more sustainable.

\section{SUMMARY}

Executed studies show, that the process of mass introduction of alternative fuels is inevitable, since it is determined by objective reasons for the limited availability of oil reserves in the world, and the growing environmental requirements. The most promising prospects, especially in our country, are those alternative fuels, the initial basis of which is natural gas. Natural gas has the best prospects as a motor fuel for mass use.

\section{CONCLUSION}

The implementation of scientific approach, which allows to take into account the prospects for the expansion of compressed gas vehicles park, as well as the risks, which may arise in the process of realization the long-term strategies for the development of this area, is presented in the form of software module. The designed method makes it possible to calculate the forecast of the demand in the CNG filling stations under optimistic and pessimistic scenarios of the market development. Monitoring of the system parameters is necessary for quickly responses to change in the situation and making grounded decisions.

The implementation of alternative fuels will not be revolutionary, but evolutionarily, with the maximum use of the existing infrastructure of the fuel market.

\section{REFERENCES}

1. Chris Woodford. Air pollution. URL: http://www.explainthatstuff.com/air-pollutionintroduction.html by. Access date: 10.05.2017

2. Makarova I.V., Khabibullin R.G., Gabsalikhova L.M, Valiev I.I. Prospects and risks of conversion of motor transport to natural gas vehicle fuel // Fundamental researches. - 2013. № 10 (Part 6). - Pp. 1209-1214.

3. Bondarenko, E.V. Increase of efficiency of operation and ecological safety of the motor transport system on the basis of resource-saving technologies: diss. of Doctor of Technical Sciences. Orenburg, OSU, 2005. - 285 p.

4. Kornilov, G.S. Theoretical and experimental justification of ways to improve environmental performance and fuel efficiency of automotive diesel engines: diss. Doctor of Technical Sciences. Moscow, NAMI, 2005. - 439 p. 
5. Johnson, E. 2003. LPG: A secure, cleaner transport fuel? A policy recommendation for Europe. Energy Policy 31 - Pp. 1573-1577.

6. Zhuang, Q., Yodotani, J., and Kato, M. 2005. Accurate measurement method for the residues inliquefied petroleum gas (LPG). Fuel 84 - Pp. 443-446.

7. Sperling, et al (1995). The target market for methanol fuel/ D. Sperling, W. Setiawan, D. Hungerford // Transportation Research Part A/ - 1995. - 29A (1). - Pp. 33-45.

8.Makarova, I., Khabibullin, R., Belyaev, E., et al. Increase of City Transport System Management Efficiency with Application of Modeling Methods and Data Intellectual Analysis. Intelligent Transportation Systems - Problems and Perspectives Volume: 32. Pp. 3780 Published: 2016.

9. Makarova, I. et al. Managing an urban transport system in enhancing the area stability. Proceedings of the 2nd International Conference on Vehicle Technology and Intelligent Transport Systems, Pp. 112-117. Year: 2016.

10. MihaelaBukljasSkocibusic, NatalijaJolic, and ZdravkoBukljas. Economic and Social Aspects of Applying Biodiesel Fuel in Road Transport Systems Telematics. Communications in Computer and Information Science. Volume 104, 2010, Pp. 243-252.

11. Carmen Difiglio and DolfGielen. Hydrogen and transportation: alternative scenarios. Mitig Adapt Strat Glob Change (2007) 12: Pp. 387-405.

12. Pascal van der Straten, Bart W. Wiegmans\&A.B.Schelling. Enablers and Barriers to the Adoption of Alternatively Powered Buses. Transport Reviews: A Transnational Transdisciplinary Journal. Volume 27, Issue 6, 2007. Pp. 679-698.

13. Order from the Minister of Investments and Development of the Republic of Kazakhstan, dated March 31, 2015, № 389 "On Establishing the Requirements for Energy Efficiency of Transport" URL: http://www.zakon.kz/4713875-ustanovleny-trebovanija-po.html.

14. Alicia A. Reich. Transportation Efficiency. Strategic Planning for Energy and the Environment. Volume 32, Issue 2, 2012. Pp. 32-43.

15. Makarova, I. et al. Dealer-service center competitiveness increase using modern management methods. Transport Problems. Volume: 7, Issue: 2, Pp. 53-59. Published: 2012.

16. Makarova, I. et al. System approach at risk management of the autoservice enterprise. Transport Problems. Volume: 8. Issue: 4. Pp. 5-16. Published: 2013.

17. Hong-Zhong Huang, Zhi-Jie Liu \& D.N.P.Murthy. Optimal reliability, warranty and price for new products // IIE Transactions (2007) 39, Pp.819-827. 
18. Mark Last, AllaSinaiski, Halasya Siva Subramania. Predictive Maintenance with Multitarget Classification Models // Intelligent Information and Database Systems. Lecture Notes in Computer Science Volume 5991, 2010, Pp. 368-377.

19. Wei Xie, Haitao Liao \&Xiaoyan Zhu. Estimation of gross profit for a new durable product considering warranty and post-warranty repairs // IIE Transactions (2014) 46, Pp.87-105.

20. J. Buddhakulsomsiri, Y. Siradeghyan, A. Zakarian\& X. Li. Association rule-generation algorithm for mining automotive warranty data // International Journal of Production Research. Vol. 44, No. 14, 15. July 2006, Pp. 2749-2770.

21. B. Rai\& N. Singh. Forecasting warranty performance in the presence of the "maturing data' phenomenon // International Journal of Systems Science. Vol. 36, No. 7, 10 June 2005, Pp. 381-394.

How to cite this article:

Gabsalikhova M L, Sadygova G R, Makarova I V, Mukhametdinov E M. The prospects of use of alternative types of fuel in road transport. J. Fundam. Appl. Sci., 2017, 9(2S), 869-879. 